\title{
EVALUACIÓN DEL ENFOQUE EDUCATIVO IMPERANTE, BASADO EN EL DESARROLLO DE COMPETENCIAS, A LA LUZ DE LA EDUCACIÓN MAYÉUTICA Rafael González Díaz*
}

RESUMEN: Dese hace tiempo, se ha consolidado un nuevo paradigma educativo, centrado en el desarrollo de "competencias", que enfatizan las actuaciones y las capacidades del estudiante "para saber hacer en un contexto". Tal enfoque está presente en muchas reformas educativas en Europa y Latinoamérica, debido a la influencia de organismos económicos internacionales. Esta artículo analiza el concepto "competencia” y su evolución, y evalúa el significado de la noción "competencia social y ciudadana" desde la educación como ejercicio de crítica y transformación social.

\begin{abstract}
9ose
ABSTRACT: For some time, a new educational paradigm has been established, based on the development of competencies. It focuses on the actions and talents of students to perform in a certain situation. This approach is present in many of the educational reforms in Europe and Latin American due to the influence of international economic organizations. This article analyzes the concept of competencies and their growth. Moreover, it evaluates the meaning of social and civil competency from an educational perspective as a critical duty and a social transformation.
\end{abstract}

PALABRAS CLAVE: competencias, filosofía de la educación, pedagogía, diálogo, justicia social. KEY WORDS: competencies, philsophy of education, pedagogy, dialogue, social justice.

RECEPCIÓN: 4 de enero de 2011.

APROBACIÓN: 9 de enero de 2011.

* Departamento Académico de Estudios Generales, ITAM. 
CITAM Derechos Reservados.

La reproducción total o parcial de este artículo se podrá hacer si el ITAM otorga la autorización previamente por escrito. 


\title{
EVALUACIÓN DEL \\ ENFOQUE EDUCATIVO \\ IMPERANTE, BASADO \\ EN EL DESARROLLO \\ DE COMPETENCIAS, \\ A LA LUZ DE LA \\ EDUCACIÓN MAYÉUTICA
}

Su alma, que debería volver llena, vuelve hinchada, porque se ha inflado desmesuradamente en lugar de crecer Montaigne, De la pedantería

\section{Introducción}

\begin{abstract}
A los noventa y nueve años de edad, uno de los más ilustres hermeneutas del siglo XX, Hans-Georg Gadamer, pronunció una conferencia sobre el sentido y los problemas de la educación. En ella, reconoció que su experiencia le resultaba insuficiente para abordar un tema tan complejo y, con humildad, se dirigió a su audiencia en estos términos: "¡Es tanto lo que quisiera aprender de ustedes!". ${ }^{1}$ Una actitud similar fue la de Kant, quien trabajó durante un período importante de su vida en la Universidad de Königsberg, impartiendo cursos sobre "pedagogía". No dudaba en aceptar que "la educación es el problema más grande y más difícil que se puede plantear al hombre". ${ }^{2}$ Expresiones parecidas se pueden encontrar en las conferencias dictadas por Nietzsche en el año 1872, y publicadas con el título Sobre el porvenir de nuestras
\end{abstract}

${ }^{1}$ Georg Gadamer, La educación es educarse, 2000, Barcelona, Paidós, p. 10.

${ }^{2}$ Immanuel Kant, Sobre pedagogía, 2008, Córdoba, Universidad Nacional de Córdoba, p. 35. 
escuelas, en las que advierte a su lector sobre la imposibilidad de sentenciar de manera definitiva en asuntos tan delicados: "Yo no prometo ni proyectos ni nuevos programas para los institutos y para las escuelas técnicas; antes bien, admiro la naturaleza exuberante de quienes están en condiciones de recorrer hasta el final del camino". 3

Estas afirmaciones reflejan las severas dificultades que tiene cualquier reflexión sobre la educación. ¿Por qué resulta complicado discurrir sobre la educación? ¿No es acaso una de las cuestiones sobre las que más se ha estudiado? ¿No es una de las soluciones esgrimidas constantemente frente a los problemas económicos, sociales y políticos?

Consideramos que los inconvenientes emanan, en primer lugar, de que el objeto sobre el que versa la reflexión no es siempre preciso; es decir, la palabra educación es rica en sentidos y multidimensional: bien puede referirse al conjunto de aprendizajes que se pretenden desarrollar en el alumno; o al proceso mismo de enseñanza-aprendizaje; o bien, puede aludir a los fines de la misma, al "sentido" o dirección final que se espera con ella. En segundo lugar, las dificultades provienen de la inevitable subjetividad que acompaña a nuestros juicios sobre el tema. Resulta muy complicado que las experiencias que hemos tenido, sea como educandos, sea como educadores, no condicionen una serie de respuestas afectivas que influyen en nuestras valoraciones. Finalmente, los problemas pueden provenir de la existencia simultánea de variados enfoques y paradigmas de la investigación educativa. Nuestra reflexión admite, también, estas dificultades y quiere interrogarse con la mayor radicalidad sobre el "sentido" o dirección final de la educación frente a las exigencias de la denominada "sociedad del conocimiento".

Desde hace más de quince años se ha consolidado un "nuevo paradigma educativo" que está centrado en el desarrollo de las denominadas "competencias". El término remite de manera inmediata a la esfera económica e industrial, y se caracteriza por enfatizar la actuación (performance) y la capacidad (competence) del estudiante para "saber

${ }^{3}$ Friedrich Nietzsche, Sobre el porvenir de nuestras escuelas, 2009, Barcelona, Tusquets editores, p. 27.

${ }^{4}$ Cfr. Posada Álvarez, "Formación superior basada en competencias, interdisciplinariedad y trabajo autónomo del estudiante", Revista Iberoamericana de Educación, http://www. rieoei.org/deloslectores/648Posada.PDF 
hacer en un contexto". ${ }^{4}$ En sus inicios, esta noción respondía de manera puntual a la exigencia de adecuación de las acciones educativas y de capacitación con las de la industria. Esta circunstancia condicionó mucho su acceso en el ámbito educativo y explica, al menos en un sentido, por qué no ha cesado de ser controvertida. No obstante, este enfoque ha ido imponiéndose y, en la actualidad, está presente en casi todas las reformas educativas en Europa y Latinoamérica. No podemos soslayar que esto ha sido posible por la influencia de un variado grupo de organismos internacionales de carácter económico y porque el concepto se ha ampliado hasta incorporar una serie de "competencias" socioafectivas, socio-culturales y de comunicación, que lo han convertido en el estándar de lo deseable para los sistemas educativos nacionales y para los organismos internacionales encargados de evaluar y orientar la política educativa internacional. ${ }^{5}$ Esta circunstancia hace indispensable identificar con precisión la naturaleza de las denominadas "competencias" y la crítica a un grupo de ellas, a las que se asigna el desarrollo de la esfera social, cultural y ciudadana, etc. Los alcances y límites de estas nociones servirán para evidenciar la importancia del diálogo como herramienta fundamental de los procesos de aprendizaje de carácter crítico y liberador. Como lo ha señalado con atingencia el ilustre educador don Carlos de la Isla: es indispensable que frente a esta visión se procure el desarrollo de la reflexión crítica, la imaginación, la creatividad y, sobre todo, el compromiso social en el alumno. Esta preocupación por la responsabilidad social del estudiante es la divisa de un compromiso con la justicia y con la dignidad de las personas.

Esta reflexión está dividida en tres grandes segmentos. En el primero, se quiere dar cuenta de la "representación del mundo" que ha condicionado el surgimiento y consolidación del paradigma de la educación basada en competencias. En segundo lugar, se analiza el concepto de competencia y su evolución. En tercero, se critica el significado y alcance de la noción de "competencia social y ciudadana", desde el horizonte de la educación como ejercicio de crítica y transformación social. Final-

${ }^{5}$ Cfr. Marco Stiefel, Berta, Competencias básicas. Hacia un nuevo paradigma educativo, 2008, Madrid, Narcea, pp. 29-43. 
mente, se propone una reflexión preliminar sobre las estrategias didácticas y las formas de evaluación que pueden vincularse con el diálogo en educación.

\section{Un mapa simbólico de nuestro mundo: la revolución del tiempo y el espacio}

En el año de 1935, Edmund Husserl dictó una conferencia que se tituló La filosofía en la crisis de la humanidad europea. En ella, defendió la tesis, emparentada con la que había formulado Wilhelm Dilthey, de que una cosa es la "naturaleza física" o "mundo" que le preocupa a las "ciencias exactas", y otra el mundo circundante de la realidad natural o "representación del mundo", que debe estudiar el hombre dedicado al cultivo de las "ciencias del espíritu". "Dicho más plenamente: el mundo circundante histórico [...] no es el mundo objetivo en el sentido nuestro, sino la 'representación del mundo' [...] esto es, su concepción subjetiva del mundo, con todas las realidades para ellos vigentes". ${ }^{6}$ Esta perspectiva nos parece útil para indagar sobre las condiciones que imperan en nuestros días. Se trata de interrogarse sobre esta formación espiritual en nosotros. Husserl se preguntaba en 1935: “¿Cómo se caracteriza la estructura espiritual de Europa? Es decir, Europa entendida no geográfica o cartográficamente, como si se pretendiera circunscribir el ámbito de los hombres que conviven aquí territorialmente en calidad de humanidad europea". ${ }^{7}$ Hoy podríamos reformular esta interrogante: ¿Cómo se caracteriza la estructura espiritual de nuestro mundo? ¿Cuáles son los rasgos de nuestro mundo circundante (Weltanschauung)?

La "representación del mundo" que impera en nuestros días se intuyó previamente en las agudas reflexiones de Romano Guardini (1960), McLuhan (1968), Drucker (1969), Alvin Tofler (1972), Daniel Bell (1973), Deleuze (1972), Alain Touraine (1975) y, posteriormente, se han enriquecido con los trabajos de Jürgen Habermas (1984), Manuel

${ }^{6}$ Edmund Husserl, Invitación a la fenomenología. La filosofía en la crisis de la humanidad europea, 1992, Barcelona, Paidós, p. 76.

${ }^{7}$ Ibid, p. 77. 
Castells (1992), Francis Fukuyama (1992), Zygmunt Bauman (2000) y Thomas Friedman (2006). Todos ellos anunciaron el advenimiento de inéditas condiciones que afectarían de manera radical el "modo" en el que percibiríamos el mundo, la sociedad y nuestra propia subjetividad. El análisis de cada uno de sus matices superaría las intenciones de la presentación que realizamos, por lo que sólo procuraremos identificar algunos de sus rasgos comunes. ${ }^{8}$

\section{La ubicuidad y la "tendencia” a la reducción}

La percepción espacial que había caracterizado a las sociedades precedentes estaba vinculada con los atributos de la rigidez y la amplitud. Se acentuaban las distancias como si éstas fueran ilimitadas, y con ello, la sensación de inmovilidad. La serenidad, la resignación, la calma y la perseverancia eran proporcionales a la sorpresa que generaban los cambios. Y aún cuando se aceptaba que las circunstancias variaran poco a poco, casi de manera imperceptible, se tenía la certidumbre de que había cimientos duraderos que no cambiarían. Las herramientas que las personas adquirían, las relaciones sociales que se cultivaban, los conocimientos y habilidades que se "enseñaban", se concebían como atributos estables, duraderos y para un uso prolongado. Esta misma impresión se tenía frente a la propia identidad, que se había construido a partir del profuso intercambio entre los miembros de una comunidad. Las costumbres, los valores y las normas se recibían como tradición estable que orientaba las acciones de los individuos y se les asignaba una permanencia indiscutible. Estas sociedades se encontraban "situadas" y desde este "centro o espacio simbólico" trataban de construir puentes

${ }^{8}$ Un ejemplo notable del efecto que tiene la relación espacial en la construcción de nuestra imagen del mundo, es el estudio de Jean Pierre Vernant, Sobre el origen del pensamiento griego, para quien "el recurso de una imagen espacial para expresar la conciencia que un grupo humano adquiere de sí mismo, el sentimiento de su existencia como unidad política, no tiene simple valor comparativo". La "representación" espacio-temporal ha constituido desde hace mucho tiempo una de las herramientas más valiosas para dilucidar las condiciones económicas, socioculturales e incluso políticas de cada época. No resulta extraño que muchos esquemas de pensamiento incorporen variadas imágenes espaciales y que hayan sido bastante útiles en investigaciones de todo tipo. 
con aquellas experiencias concurrentes, que, paradójicamente, se percibían como no simultáneas.

En contraste, las diversas imágenes del mundo que se han ensayado hasta el momento, describen un proceso continuo de reducción efectiva de las relaciones espacio-tiempo como resultado del vertiginoso avance de las tecnologías del procesamiento de la información y la comunicación. Las distancias pierden relevancia en virtud de los poderes de conexión e interactividad de que se dispone, haciendo flexible las posibilidades de intervención en una red global. Esta circunstancia ha provocado que el "centro o espacio simbólico" pueda ubicarse en cualquier latitud del globo, y que sea indiferente, salvo como puerta de acceso, a un mundo limitado que permite interacciones ilimitadas. El mundo, entonces, parece comprimido, interconectado y cambiante. Su correlato es el de la transitoriedad y de la inmediatez. Es decir, el cambio es continuo, impetuoso, y provoca en las personas una sensación de fugacidad e inestabilidad que afecta cualquier esfera de la vida. Los objetos que nos rodean, las relaciones que construimos y las conquistas intelectuales que realizamos se perciben como transitorias; no permanecen, de la misma manera que nuestros valores e identidad. Estas condiciones han sido posibles por los desmesurados avances en las tecnologías de procesamiento de la información y la comunicación. "Entre las tecnologías de la información incluyo como todo el mundo, el conjunto convergente de tecnologías de la microelectrónica, la informática (máquinas, software), las telecomunicaciones/televisión/radio y la optoelectrónica. Además [...] también incluyo en el ámbito de las tecnologías de la información, la ingeniería genética y su conjunto de desarrollos y aplicaciones en expansión". ${ }^{9}$ Con relación a estas tecnologías, no se pueden obviar los indiscutibles descubrimientos en materiales, mecanismos de elaboración (como la nanotecnología), fuentes de energía, transportes y aplicaciones terapéuticas. No se trata sólo de otorgar al conocimiento y la información una trascendencia para la generación de útiles, sino en la aplicación de tales conocimientos al desarrollo de aparatos que generan más conocimiento y procesamiento de la infor-

${ }^{9}$ Manuel Castells, La era de la información, 2002, México, Siglo XXI, p. 56. 
mación en un círculo que acelera la innovación y sus diversos usos. En realidad, "las nuevas tecnologías de la información no son sólo herramientas para aplicar, sino procesos que desarrollar". ${ }^{10}$

Resulta coherente que la mayoría que se represente al mundo como una esfera sometida a un movimiento concéntrico de "limitación espacial" (Romano Guardini), ${ }^{11}$ otros utilizaron expresiones como "aldea global" (Mc Luhan), "la tierra es plana" (Thomas Freidman), ${ }^{13}$ o la "modernidad líquida" (Bauman) ${ }^{14}$ para señalar la nueva "vecindad" que producen las nuevas tecnologías. En variadas ocasiones, se utilizó la expresión "era" para calificar el volumen, magnitud y naturaleza de los cambios que se estaban operando en los procesos de manufactura, de innovación tecnológica y de conocimiento (Toffler, Touranie, Bell). ${ }^{15}$ Expresiones análogas son la "sociedad del conocimiento" (Peter Drucker), 16 "sociedad de la información” y "sociedad red" (Manuel Castells). ${ }^{17}$

\section{La desorientación y el conflicto}

El impacto que esta reducción de las categorías espacio-temporales tiene en la percepción subjetiva de los individuos, y en la organización social, ha sido uno de los aspectos que más ha preocupado a los diferentes investigadores. La mayor parte de los análisis coinciden en que este nuevo escenario supone la ruptura radical del viejo orden jerárquico o central, para dar paso a una experiencia multifocal que reta las capaci-

${ }^{10} \mathrm{Ibid}, \mathrm{p} .58$.

${ }^{11}$ En el texto El ocaso de la Edad moderna, Guardini aceptaba que "la nueva experiencia es precisamente la limitación del mundo", Romano Guardini, Obras de Romano Guardini, t. I, El ocaso de la edad moderna, 1981, Madrid, Ediciones Cristiandad, p. 72.

${ }^{12}$ Cfr. Marshall McLuhan, Guerra y paz en la aldea global, 2003, Barcelona, PlanetaAgostini.

${ }^{13}$ Cfr. Thomas Friedman, La tierra es plana, 2007, España, mrediciones.

${ }^{14} \mathrm{Cfr}$. Zygmunt Bauman, Modernidad líquida, 1999, México, FCE.

${ }^{15}$ Cfr. Alvin Tofler, El shock del futuro, 1972, México, FCE; Alain Touraine, La era postindustrial, 1969, Barcelona, Ariel; y, Daniel Bell, El advenimiento de la sociedad post-industrial, 1973, Madrid, Alianza.

${ }^{16}$ Cfr. Peter Drucker, The age of discontinuity, 1969, New York, Harper \& Row.

${ }^{17}$ Cfr. Castells, op. cit. 
dades de adaptación de los individuos y de las organizaciones, tanto públicas como privadas. Resulta previsible que una enorme cantidad de cambios a velocidad acelerada causen una fuerte dosis de desorientación en los individuos dentro de su misma cultura.

La incertidumbre y la ansiedad serán el plasma que condicione muchas de las manifestaciones sociales, puesto que las personas se enfrentarán, de manera permanente, con la innovación en la esfera personal y profesional. Los hábitos que se habían convertido en fuente de sentido para numerosos individuos se verán sometidos a presiones heterónomas y a modificaciones inevitables. Se anticipa que estas dificultades de adaptación se puedan expresar en una doble vertiente: en algunos casos, sobre todo para los individuos con menor capacidad de adaptación, se pueden predecir intensos mecanismos reactivos y de afirmación fanática al pasado y a los contenidos que les otorgaban certidumbre; en otros, sobre todo entre los más jóvenes, para quienes el cambio y la interactividad serán como su atmósfera vital, se espera una falta de asidero histórico y anímico. Los problemas para este último grupo se concentrarán en la selección, análisis y discernimiento de un volumen de información que crece de manera continua, y en la construcción de sus propias percepciones y juicios. Para ambos grupos, la disolución de una "cultura" de lo sólido y lo permanente significa la co-existencia en una sociedad donde los compromisos serán frágiles, intercambiables o transitorios. Además de las dificultades de adaptación que hemos reseñado, se intuye que la vecindad y los desplazamientos que ocasiona una sociedad interconectada producirá una manifestación de intolerancia social y profundos conflictos económicos, sociales y políticos.

\section{La alienación y la resistencia}

La desorientación será uno de los rasgos que acompañen el devenir de nuestras sociedades, y, de manera concomitante, el surgimiento de una conflictividad que puede parecer inevitable, porque la velocidad de los cambios y las exigencias de adaptación serán cada día mayores. Frente a estas exigencias ambientales, se presumen dos actitudes bási- 
cas: en un extremo, se puede esperar un proceso profundo de alineación, conformidad e indiferencia; en el otro, un fortalecimiento de mecanismos de resistencia que busque dirigir los cambios. Sobre el primer tipo de manifestaciones, Alain Touraine advertía que de las nuevas capacidades para operar el cambio se pueden esperar nuevas formas de control de las necesidades, que produzcan una alienación sutil, pero efectiva. Entre las formas de alienación social está la tendencia desmesurada por el consumo y el control de los discursos "permitidos", que darían forma a la denominada "sociedad programada". Una de las formas de "dominación social" que más le preocupaba era la "manipulación cultural", que condiciona las actitudes, las necesidades y la noción de trabajo. Rasgo típico es "el dominio de la sociedad por grandes organizaciones, que son al mismo tiempo político-económicas". ${ }^{18}$ Finalmente, este nuevo paradigma social está acompañado de una nueva distribución de poderes que sólo pueden detentar aquellos que se procuren la novedosa fuente de valor, es decir, la información y el conocimiento. En oposición a este proceso de adaptación acrítico, se han levantado voces que invitan a redescubrir en la "resistencia" frente a la violencia simbólica, el mecanismo para la subversión de este "orden" injusto. La reflexión crítica, el despertar de una nueva subjetividad y la consolidación de nuevas formas de organización, flexibles y locales, son los ingredientes de la subversión frente a dicho "pensamiento único". ${ }^{19}$

\section{La prospectividad}

Los estudios prospectivos han sido muy socorridos en los últimos años. La tradición fue iniciada en los años setenta con los trabajos de Daniel Bell, Alvin Toffler y el mismo Peter Drucker. Desde entonces, la preocupación por estudiar el "futuro" ha generado interés y se ha considerado oportuno para la toma de decisiones, especialmente en medio de los

${ }^{18}$ Alain Touraine, op. cit., pp. 7-9. Recomiendo la revisión de su obra Cartas a un estudiante; en ella, se encontrarán agudos análisis de los procesos de alienación a que se ven expuestos las sociedades postindustriales y sus nexos con un mundo comunicado técnicamente.

${ }^{19}$ Cfr. Pierre Bourdieu, Contrafuegos, 1999, Barcelona, Anagrama. 
cambios rápidos e interrelacionados, porque representan una herramienta valiosa para preveer situaciones indeseadas, así como ofrecer alternativas. Definitivamente, la aportación que ciertas predicciones pueden ofrecer dependerá del rigor empleado en su confección y en una visión multidisciplinar. Estas mismas consideraciones hacen interesante la revisión de algunas de las tendencias que el estudio Delfos reseña en la investigación Megatendencias para el siglo XXI para los próximos 50 años. En el escenario económico, se espera una "hegemonía" del sistema capitalista y un crecimiento sostenido concentrado en muy pocas manos. "Al contrario, el proceso parece inverso: cada vez menos disponen de más y más de menos, en un mundo con capacidad tecnológica y de recursos como para alcanzar un desarrollo integral y más igualitario". ${ }^{20} \mathrm{Se}$ advierte un protagonismo creciente de las grandes corporaciones que, si bien no eliminarán a las empresas locales, serán los verdaderos actores de la economía mundial. También se considera como elemento neurálgico la emergencia a corto plazo de una nueva zona económica de hegemonía mundial, con Asia como su protagonista. "África y Latinoamérica parecen seguir la tendencia a 'desaparecer' del mapa económico mundial en el contexto de una economía global, de cara al siglo XXI. Asia se revela como el contrapeso definitivo a la tradicional hegemonía de Europa y Norteamérica en el siglo XX" ${ }^{21}$ Se anticipa una total computarización de la vida humana en los países desarrollados hacia el primer cuarto del siglo; esto incluye equipamientos automáticos, uso extendido del comercio electrónico, teletrabajo (alrededor de un 50\% de la población) y uso masivo de Internet (alrededor de 90\%). Se intuye que algunas innovaciones e iniciativas alternas que emprendan grupos de individuos a escala global se impondrán como factor de cambio. En algunos casos, los conflictos con movimientos sociales emergentes en países desarrollados adquirirán relevancia e incluso matices violentos.

En el escenario político, se prevé la extensión del sistema democrático y la inclusión de mecanismos sofisticados de participación pública en los procesos de toma de decisiones políticas, gracias a las nuevas

\footnotetext{
${ }^{20}$ Enric Bas, Megatendencias para el Siglo XXI. Un estudio Delfos, 2004, México, FCE, p. 137. ${ }^{21}$ Ibid, p. 138.
} 
tecnologías. "En el 2050, los sistemas basados en Internet serán ampliamente utilizados (tanto en dictaduras como en las democracias) para el control político y de la opinión pública". ${ }^{22}$ Hacia el 2025, se presume la conformación de un sistema mundial, formado por entidades con facultades para decidir a escala mundial. En ella convergerían políticos de los Estados nacionales, representantes de organismos de la sociedad civil y de las grandes corporaciones internacionales. Este tipo de organizaciones se coaligarían ad hoc con la ONU como principal organismo director. Dichas organizaciones harían explícita la subordinación de las actividades políticas a las económicas. "El papel mediador de los organismos internacionales de gestión política [...] se prevé como el segundo puntual en la toma de decisiones políticas". ${ }^{23}$ En el 2025, se espera la ascensión de partidos políticos extremistas, principalmente en zonas polarizadas y con problemas de subdesarrollo, y una participación equitativa de la mujer en la toma de decisiones políticas.

En la esfera cultural, el estudio sugiere que hacia el año 2050 se impondrá una cultura global (de rasgos occidentales) con menor impacto en los países más pobres, como resultado de su poca accesibilidad a los medios de comunicación. Simultáneamente y en distintos niveles, convivirán proyectos culturales locales que también tendrán su espacio de difusión. La comunicación electrónica jugará un papel relevante en esta “colonización cultural” y el inglés se convertirá en el idioma universal de la economía, la política y la cultura hacia el año 2050. Algunas culturas e idiomas podrán perder cierta originalidad debido al proceso de globalización. También resulta relevante que las nuevas tecnologías introducirán cambios drásticos en el ámbito educativo. "En el 2050 la mayoría de los estudiantes desarrollarán sus capacidades y el acceso a la educación desde su hogar por medio de recursos electrónicos". ${ }^{24}$ Entre los cambios que experimentarán los sistemas educativos están el crecimiento de la tele-educación y la incapacidad de control curricular por parte de los Estados; en el mismo sentido se encamina la reflexión de José M. Esteve, para quien las nuevas tecnologías de la información y

${ }^{22}$ Ibid, p. 153.

${ }^{23} \mathrm{Ibid}, \mathrm{p} .148$.

${ }^{24} \mathrm{Ibid}, \mathrm{p} .166$. 
la comunicación van a completar los profundos cambios de la tercera revolución educativa, que colocan al aprendizaje sobre la enseñanza. ${ }^{25}$ Otro fenómeno cultural, que se consolidará en los primeros 25 años del siglo XXI, será el crecimiento de comunidades virtuales y grupos de interés. Los individuos formarán parte de comunidades electrónicas, muchas de ellas de carácter alternativo, en las que participarán de modo intenso, desplazando incluso a las comunidades locales reales. En la dimensión ecológica, se espera un gran movimiento migratorio proveniente de los países subdesarrollados. Una concentración de la población en las ciudades, sobre todo hacia el año 2050 (75\%) y la vulneración progresiva de la privacidad individual por la extensión de los sistemas de vigilancia electrónicos y el uso de datos personales.

\section{La educación entendida como desarrollo de "competencias"}

\section{El origen de la noción de "competencia"}

En 1991, la Conferencia General de la UNESCO convocó a "una comisión internacional para que reflexionara sobre la educación y el aprendizaje en el siglo XXI". Los trabajos fueron coordinados por Jacques Delors y comenzaron oficialmente en el año 1993. El resultado de este proyecto es el conocido Informe a la UNESCO: "La educación encierra un tesoro"; en él, se reconoció que la primera tarea que tiene la educación en un mundo convulso e inequitativo es que debe poseer un calado profundamente ético y cultural. Sólo desde esta perspectiva se pueden "ordenar" y "dirigir" la innovación, la sociedad del conocimiento, la producción de bienes o servicios y los avances tecnológicos. Debe permitir a todos, sin excepción, hacer fructificar sus talentos y capacidades; ayudarles en el proceso de autocomprensión y de crítica. También tiene la responsabilidad de favorecer la comprensión del otro en su particularidad y el devenir del mundo. La comisión estimó que "la educación debe estructurarse en torno a cuatro aprendizajes fundamentales que en el trascurso de la vida serán para cada persona, en cierto sentido, los pilares del

${ }^{25}$ José Esteve, La tercera revolución educativa, 2003, Barcelona, Paidós, p. 236. 
conocimiento: aprender a conocer, es decir, adquirir los instrumentos de la comprensión; aprender a hacer, para influir sobre el propio entorno; aprender a vivir juntos, para participar y cooperar con los demás en todas las actividades humanas; por último, aprender a ser, un proceso fundamental que recoge elementos de los tres anteriores. Por supuesto, estas cuatro vías del saber convergen en una sola, ya que hay entre ellas múltiples puntos de contacto, coincidencia e intercambio". ${ }^{26}$ Resulta muy interesante constatar que la comisión insistiera repetidamente que uno de los cuatro pilares es especialmente importante. "Se trata de aprender a vivir juntos conociendo mejor a los demás, su historia, sus tradiciones y su espiritualidad [... U Una utopía, pensarán, pero una utopía necesaria, una utopía esencial para salir del peligroso ciclo alimentado por el cinismo y la resignación". ${ }^{27}$ El documento no propone el desarrollo de competencias como elemento rector de las acciones educativas, sino que lo vincula con el pilar aprender a hacer. Anuncia la caducidad de la noción tradicional de calificación profesional por la de competencia como resultado de las transformaciones aceleradas en el sector industrial. Recomienda no limitarse al dominio de un oficio sino adquirir una competencia que permita enfrentar numerosas situaciones inéditas e imprevisibles. En realidad, las preocupaciones de la Comisión Internacional se centraron en la necesidad de atender, como prioritarios, los problemas de convivencia, de diálogo con otras identidades culturales, de autoconomiento, autonomía, juicio crítico y responsabilidad en la realización de un destino colectivo. Estas mismas preocupaciones se encuentran en la reflexión de Edgar Morin sobre el pensamiento complejo, ${ }^{28}$ para quien hay siete saberes "fundamentales" que la educación debe procurar; entre los más destacados están: la capacidad para evaluar críticamente el conocimiento en sus contextos complejos, el desarrollo de la comprensión mutua y la edificación de una ética del género humano. "Se trata de armar cada mente en el combate vital para la lucidez". ${ }^{29}$

${ }^{26}$ Jacques Delors, La educación encierra un tesoro, 1996, Madrid, Santillana, pp. 95-6.

${ }^{27}$ Ibid, p. 22.

${ }^{28}$ Edgar Morin, Educar en la era planetaria, 2006, Barcelona, Gedisa, pp. 51-73.

${ }^{29}$ Edgar Morin, Los sietes saberes necesarios para la educación del futuro, 1999, Madrid, UNESCO, p. 1; cfr. del mismo autor, Breve historia de la barbarie en Occidente, 2007, Bs. As., Paidós. 
El término "competencia" procede "aparentemente" del mundo de la empresa, de las técnicas de management y de los procesos de selección de personal. En estas esferas, se habla desde hace mucho tiempo de gestión por competencias como del método que precisa las capacidades necesarias para desempeñarse de manera idónea en un puesto. Uno de los primeros estudios fue el de David McClelland, un afamado psicólogo y profesor de la Universidad de Harvard, contratado por el Departamento de Estado norteamericano; desarrolló un estudio orientado a la mejora de los procesos de selección de personal. El proyecto se dirigió a la detección de las características de aquellos empleados que se desempeñaban de manera exitosa y se confrontaba con los perfiles de los candidatos. Los resultados arrojaron que el buen desempeño de los nuevos empleados no estaba en proporción a sus conocimientos o habilidades, sino a sus "competencias", experiencias previas o incluso en su biografía. El estudio se publicó en el año 1973 con el título de "Testing for Competence Rather Than for "Intelligence". ${ }^{30} \mathrm{La}$ "competencia" suponía la integración de una serie de aprendizajes conceptuales, destrezas e incluso actitudes que se deberían de deducir de las personas con excelente desempeño. Investigaciones posteriores se han interrogado sobre la actuación (performance) de las personas expertas. ${ }^{31}$

Sin embargo, el concepto de competencias fue tomado de la lingüística; Noam Chomsky, en 1965, publicó “Aspectos de la teoría de la sintaxis", en el que adicionó a sus teorías sobre la gramaticalidad-referidas a las respuestas espontáneas de los hablantes en su misma lengua-la distinción entre "actuación" (performance) y "competencia" (competence). El primero se refiere a la conducta lingüística observable (actuación); el otro, a las precondiciones internas que subyacen en ella

${ }^{30}$ David McClelland, “Testing for rather for Intelligence”, American Psychologist, 1973, 28, January, pp. 1-14.

${ }^{31} \mathrm{Cfr}$. Anders Ericsson et al., Development of Professional Expertise: Toward Measurement of Expert Performance and Design of Optimal Learning Environments, 2009, Cambridge, Cambrigde University Press. Cfr. también Expertise and Expert Performance, 2006, Cambridge, Cambridge University Press; Soriano de Alencar et al., "La relación entre creatividad y expertise: contribuciones teóricas y empiricas”, Revista de psicología, 2009, vol. XXVII (1), Pontificia Universidad Católica del Perú. 
(competencia). Chomsky acepta que la competencia es una especie de abstracción o facultad imaginaria (mental o psicológica) separada de la producción efectiva y real de oraciones. Un conjunto de reglas subyacentes de las actuaciones. ${ }^{32}$

Este enfoque, eminentemente pragmático, que acompañó en su origen al concepto de competencia, explica las reticencias con las que fue recibido en el universo educativo y las controversias conceptuales que sigue generando. No obstante, su presencia en la esfera educativa fue adquiriendo importancia debido a su inclusión en la mayor parte de las agendas de influyentes organismos internacionales. El ejemplo paradigmático es el Programa Internacional de Evaluación de Estudiantes de la OCDE (Programme for International Student Assesment, PISA), que se ha dado a la tarea de aplicar una prueba estandarizada en matemáticas, lengua y ciencias, a jóvenes de 15 años de las naciones más industrializadas. Este programa manifestó, de inmediato, mucho interés por la noción de competencias básicas, es decir, la serie de capacidades, base de otras destrezas de mayor complejidad. La Unión Europea en el Consejo Europeo de Lisboa del año 2000 eligió este mismo enfoque; en sus conclusiones, se aceptó que los países de la Unión se enfrentan a enormes cambios, fruto de la mundialización y de la nueva economía, basada en el conocimiento, y que se debería moldear dichos cambios de manera coherente. El objetivo estratégico era el de "convertirse en la economía basada en el conocimiento más competitiva y dinámica del mundo, capaz de crecer económicamente de manera sostenible con más y mejores empleos y con mayor cohesión social". ${ }^{33}$ Entre las acciones que se sugirieron, se pueden identificar el fomento de la adquisición de nuevas competencias básicas y la necesidad de crear un marco europeo que definiera las "nuevas cualificaciones en materia de TI, idiomas extranjeros, cultura tecnológica, espíritu empresarial y habilidades para la socialización". ${ }^{34}$

${ }^{32} \mathrm{Cfr}$. Chomsky, Aspectos de la teoría de la sintaxis, 1965, Madrid, Aguilar.

${ }^{33}$ Consejo Europeo de Lisboa, Conclusiones de la presidencia, 2000, Bol. UE 3, p. 1., en: http://www.europarl.europa.eu/summits/lis1_es.htm [5 de marzo de 2010].

${ }^{34} \mathrm{Ibid}$, p. 8. 
Estos primeros planteamientos dieron inicio a una carrera que buscaba determinar el conjunto de competencias básicas que deben ser objeto de los diferentes curricula. El primer proyecto sistemático se realizó auspiciado por la OCDE. El programa se llamó Definition and Selection of Competencies (DeSeCo), ${ }^{35}$ y se encargó de "definir" y seleccionar las "habilidades" y "competencias" esenciales para la vida personal y social. Su primer documento de síntesis se publicó en el año 2005. Le seguiría el programa de PISA, en su edición 2006, donde se redefinieron los proyectos de evaluación estandarizada desde la óptica de las competencias. En la Unión Europea se “definieron” las competencias básicas con la aprobación parlamentaria del documento Competencias clave. Textos aprobados por el parlamento europeo, el 26 de septiembre de $2006^{36}$ y con la publicación de un segundo texto de recomendaciones parlamentarias, el 18 de diciembre de $2006 .{ }^{37}$

En México también se ha incorporado la misma terminología y se ha definido el conjunto de competencias básicas en el nuevo Plan de Estudios (2006) de la Secretaría de Educación Pública (SEP). En la presentación del mismo, se asegura que la razón de ser de la educación secundaria es "asegurar que los jóvenes logren y consoliden las competencias básicas para actuar de manera responsable consigo mismos, con la naturaleza y con la comunidad de la que forman parte, y participen activamente en la construcción de una sociedad más justa, más libre y democrática", 38

${ }^{35} \mathrm{Cfr}$. OCDE-DeSeCo, Definition and Selection of Competencies: Executive Summary, 2005, Paris, en: http://www.oecd.org/document/17/0,3343,en_2649_39263238_2669073_ 1_1_1_1,00.html [5 de marzo de 2010].

${ }^{36}$ Cfr. Parlamento europeo, Competencias clave. Texto aprobado por el parlamento europeo. Estrasburgo. Aprendizaje permanente, 2006, Estrasburgo, en: http://www.europarl. europa.eu/sides/getDoc.do?pubRef=-//EP//NONSGML+TA+P6-TA-2006-0365+0 $+\mathrm{DOC}+\mathrm{PDF}+\mathrm{V} 0 / / \mathrm{ES}$ [5 de marzo de 2010].

${ }^{37} \mathrm{Ibid}$., Recomendaciones del parlamento europeo y del consejo sobre las competencias clave para el aprendizaje permanente, 2006, Bruselas, en: http://eur-lex.europa.eu/LexUriServ/LexUriServ.do?uri=OJ:L:2006:394:0010:0018:ES:PDF [5 de marzo de 2010].

${ }^{38}$ Cfr. SEP, Plan de Estudios 2006, México, SEP, p. 6. 


\section{La naturaleza de las competencias}

La noción de competencia es ambigua porque no hay un concepto único para su uso; sin embargo, se ha convertido en uno de los temas centrales y más debatidos frente al acuerdo tácito de que un modelo tradicional de transmisión de conocimientos no puede preparar al estudiante para responder a escenarios complejos, cambiantes y muchas veces inéditos. De manera general, se puede decir que la noción de competencia está relacionada con esa capacidad para enfrentar situaciones complejas, lo que implica superar el nivel de los aprendizajes conceptuales, procedimentales e incluso actitudinales, adquiridos en los procesos de educación formal, no formal e informal, y movilizarlos en situaciones concretas. De acuerdo con el proyecto DeSeCo (2005) de la OCDE, "una competencia se define como la habilidad para satisfacer con éxito exigencias complejas en un contexto determinado, mediante la movilización de prerrequisitos sociales que incluyen tanto aspectos congnitivos como no cognoscitivos". ${ }^{39}$ Deberían de contribuir a la conquista de resultados valiosos para el individuo y la sociedad, y ayudar a los individuos a enfrentar demandas importantes en una amplia variedad de contextos, sin dejar de ser relevantes. Es fácil notar que el enfoque de DeSeCo está orientado a la demanda externa o funcional; sin embargo, necesita ser complementada por una conceptualización internamental. "Cada competencia se construye en cuanto combinación de habilidades cognitivas y prácticas interrelacionadas, conocimiento (incluido el tácito), motivaciones, valores, actitudes, emociones y otros componentes sociales y de comportamiento que se movilizan a la vez para llevar a cabo una acción efectiva". ${ }^{40}$ Sin embargo, las competencias se observan en las acciones contextualizadas.

Esta definición del proyecto DeSeCo, tuvo como antecedentes el estudio de Franz E. Weinert Concepts of Competence ${ }^{41}$ en el que se

\footnotetext{
${ }^{39}$ Simone Rychen et. al., Las competencias clave para el bienestar personal, social y económico, 2006, OCDE, p. 74.

${ }^{40}$ Marco Stiefel, op. cit., p. 32.

${ }^{41}$ Cfr., Franz Weinert, Concepts of Competence, 1999, Munich, Max Planck Institute for Psychological Research.
} 
describen los principales usos semánticos de la expresión. Todos ellos afines a las nociones de ability (habilidad), aptitude (aptitud), capability (capacidad), competence (competencia), effectiveness (efectividad) y skill (destreza). El estudio aclara que, si bien el concepto de competence (competens, entis) en sentido etimológico tiene una larga historia de variaciones desde la lengua latina, referido a "conocimiento" o "responsabilidad”, el sentido en psicología, sociología, lingüística, política o economía es aproximadamente el de un sistema especializado, individual o colectivo, de habilidades, maestrías, o destrezas necesarias o suficientes para alcanzar una meta específica. ${ }^{42}$ También fue decisivo el trabajo de Philippe Perrenoud, en el que se pueden identificar tres de los atributos que se asignan al concepto de competencia. "El concepto de competencia representará aquí una capacidad de movilizar varios recursos cognitivos para hacer frente a un tipo de situaciones". Una definición que se puede descomponer en cuatro aspectos. En primer lugar, las competencias "no son en sí mismas conocimientos, habilidades o actitudes, aunque movilizan, integran, orquestan tales recursos". Las competencias suponen el "desarrollo de unas condiciones de posibilidad" y esto se logra con la integración de aprendizajes conceptuales, factuales, procedimientos, destrezas, actitudes que se pueden cultivarse en la educación formal, en algunos grupos de educación no formal como el de los clubes, asociaciones, y en cualquier interacción cotidiana, que se denomina educación informal (movilizan). En segundo lugar, la movilización es pertinente "en situación, y cada situación es única", aunque puede ser referida a otra análoga que ya ha sido conocida. Esto implica la trasferencia de los aprendizajes de unos contextos a otros, de aquellos de la vida a los de la escuela o del mundo del trabajo (desempeño y aplicabilidad). En tercero, el "ejercicio de la competencia pasa por operaciones mentales complejas, sostenidas por

${ }^{42}$ Se recomienda la revisión del denominado "enfoque de las capacidades": Capabilities approach, del afamado economista Amartya Sen, quien insiste en que "las capacidades" no son equiparables con el aumento de la producción económica, sino con las cosas que las personas pueden realmente hacer o ser (los funcionamientos). Formalmente, la capacidad para funcionar añade a la noción de funcionamiento, la posibilidad real de escoger o no funcionar así. [En este sentido, se puede revisar Mathias Nebel, "Fundamentos éticos de la capabilidad de afiliación", en Estudios, núm. 83, pp. 45-78, N. del E.] 
esquemas de pensamiento", que permiten identificar y realizar una acción situada. No es, por tanto, un simple hacer. El "saber hacer" se equipara con habilidades concretas. En este caso, las competencias son "una habilidad de alto nivel", un salto a nivel intelectual (habilidad compleja). En cuarto lugar, las competencias se expresan en la capacidad de hacer sinergia para abordar situaciones-problema, por eso la competencia se mide en la acción concreta (situada). "En resumen, el análisis de competencias remite constantemente a una teoría del pensamiento y de la acción situados. ${ }^{43}$ Esta perspectiva de la noción de competencia ha generado inquietudes en muchos psicólogos, sobre todo de habla inglesa, por el estudio de las "virtudes". Para algunos, la distinción entre el concepto "virtud" y "competencia" es, en la práctica, inexistente. Esta discusión tendría que ampliarse, pero no es objeto de este trabajo. $^{44}$

\section{1 Las competencias básicas: su tipología}

El proyecto DeSeCo, del que ya hemos hablado, propuso tres grandes categorías para clasificar las competencias. La primera, vinculada a todas las herramientas para interactuar efectivamente con el ambiente (físicas, tecnológicas y socioculturales). La segunda, y como resultado de la interdependencia, la necesidad de los individuos de comunicarse con otros, sobre todo en grupos heterogéneos. Finamente, se necesita fomentar la responsabilidad para manejar la propia vida y situarla en un contexto social más amplio para actuar de manera autónoma. ${ }^{45}$ Por su parte, el Parlamento europeo definió las competencias "como una combinación de conocimientos, capacidades y actitudes adecuadas al contexto"; estableció ocho competencias clave: a) comunicación en lengua materna; b) comunicación en lenguas extranjeras; c) competencia matemática y competencia básica en ciencia y tecnología; d) compe-

${ }^{43}$ Philippe Perrenoud, Diez nuevas competencias para enseñar, 2007, México, Colofón, p. 11.

${ }^{44}$ M. Macaulay et al., "From virtue to competence: changing the principles of public service", Public Administration Review, 2006, 66 (5), pp. 702-10.

${ }^{45}$ OCDE-DeSe-Co, op. cit, p. 4. 
tencia digital; e) aprender a aprender; f) competencias sociales y cívicas; g) sentido de la iniciativa y espíritu de empresa; y, h) conciencia y expresión culturales. ${ }^{46}$ Estos textos han orientado todas las reformas europeas e incluso algunas en Latinoamérica. La reforma en México ha tratado de "adaptarlas", y se encuentran muchos puntos de contacto. El Plan de Estudios 2006 de la Educación Secundaria refiere cinco competencias generales: a) para el aprendizaje; b) para el manejo de la información; c) para el manejo de situaciones; d) para la convivencia; y, e) para al vida en sociedad.

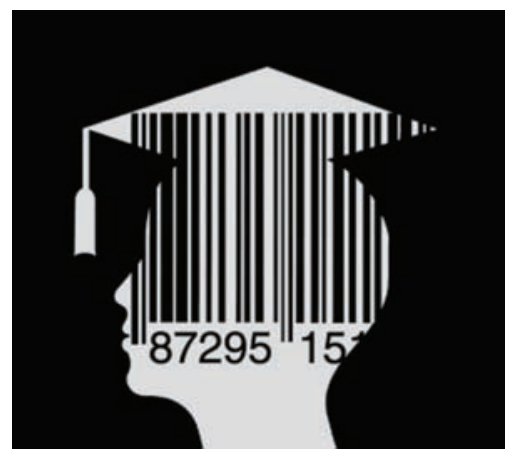

http://lahistoriadeldia.wordpress.com/2009/10/20/

\section{El significado y alcance de la noción de competencia}

1. La "competencia" supone un ojo aguzado que no mira a los fines necesariamente

El primer aspecto que nos invita a la reflexión es la perenne discusión entre los fines y los medios. Las competencias están orientadas al desarrollo de esas "condiciones de posibilidad" para alcanzar fines o emprender acciones que buscan responder a demandas inéditas. Esta circunstancia hace necesaria no tanto su definición, sino la de los fines que se buscan alcanzar con ellas. Luego, no hay competencias buenas si no sabemos lo que se quiere conseguir. Nadie podría sentirse satis-

\footnotetext{
${ }^{46}$ Parlamento europeo, op. cit, p. 13.
} 
fecho si tuviera la certeza de que las instituciones escolares y el proceso educativo favorecen, de manera recurrente, el egreso de estudiantes eficaces, fríos, calculadores, indiferentes, petulantes o cínicos. Y ello porque la educación siempre se ha visto como depositaria de un conjunto de demandas sociales que superan la urgente necesidad de adaptación al medio. Esta situación coloca toda reflexión sobre la educación bajo una sombra de sospecha y crítica. Sospecha, en primer lugar, porque no existe "modelo educativo neutral"; la educación siempre constituye una forma de prescripción, es el resultante de una visión del mundo y del hombre que pretende ser normativa. En segundo lugar, porque los discursos explícitos de la escuela no corresponden, muchas veces, con aquello que denominó Philip Jackson como curriculum oculto, es decir, el conjunto de prácticas sociales que educan de manera implícita. Esta situación nos coloca en un escenario difuso puesto que, al tiempo que proclamamos una educación crítica y humanista, podemos estar reproduciendo la lógica de los "poderes sociales o económicos" que rechazamos discursivamente. Estas tensiones entre lo que el "entorno" demanda y aquello que se "valora" como indispensable, han acompañado la reflexión de la mayoría de nuestros filósofos y reformadores sociales. ${ }^{47}$ En contraste con lo que sucede en otros campos del conocimiento, es notoria la convergencia de la mayoría de los autores: ninguno se ha atrevido a señalar que debe ser el objeto de la educación la pura acumulación de conocimiento, la indiferencia frente a los problemas sociales que experimenta la comunidad, la especialización miope, la reproducción estandarizada de estudiantes, etc.

Quiero llamar la atención sobre la persuasiva crítica realizada por Miguel Montaigne, el humanista del siglo XVI, quien advertía en sus ensayos pedagógicos, especialmente en el destinado a reflexionar sobre

${ }^{47}$ A nadie le resulta extraña la severa crítica realizada por Platón en la República a los métodos de enseñanza vigentes entre los griegos (Pl., R., 376 $\mathrm{a}$-383); tampoco debe pasar inadvertida la preocupación eminentemente didáctica de la Patrística, sea en las confidencias que San Agustín vierte en sus Confesiones (I, VIII, IX) o en sus formulaciones del De Magistro, sea en aquel notable esfuerzo de Clemente de Alejandría (El pedagogo, I, 16), por no hablar de la Edad Media. En el siglo XVII, Comenio y, posteriormente, la Ratio Studiorum de los jesuitas, permitirían la inclusión de conceptos vigentes hasta nuestros días, como el del Syllabus o Disciplina. En la época moderna, múltiples reformadores han criticado con agudeza estas contradicciones y han pretendido abonar al "sentido" de la educación. 
la evidente pedantería que distinguía a los especialistas de la época y que considero idónea para describir lo que puede suceder en muchas de nuestras instituciones educativas, en las que no resulta extraño, en la práctica escolar, un afán cuantitativo y efectista que provoca el embotamiento de las capacidades de juicio en el alumnado. Decía que "así como hay plantas que se mueren por exceso de abono, y lámparas que se apagan por exceso de aceite, hay espíritus que se embrollan y oscurecen con el exceso de estudio y de conocimientos; porque abrumados por tanta diversidad de materias, no aciertan a desenredarse, y la carga les fuerza a estar encorvados y encogidos". ${ }^{48}$ Montainge no considera inoportuna la formación especializada, ni el cultivo del griego, el latín o de las formas retóricas en los estudiantes, pero mira con desconfianza que "no nos cuidemos de averiguar si ha ganado en bondad o cordura, y esto que habría de ocupar el primer lugar, queda en último término". ${ }^{49}$ Esta capacidad que denomina "el discreto juzgar" es todavía más importante que la ciencia y el saber especializado. Porque éste puede prescindir de lo primero, pero la ciencia no debería nunca dejar de lado el recto juicio. La presencia de estos elementos es el criterio definitorio de un sistema educativo, pues "no se trata sólo de aprender como con alfileres el saber en el alma, sino de apropiárselo: no hay que rociarla ligeramente de sabiduría, sino empaparla y teñirla; y si después de todo nuestra alma no se mejora y purifica saliendo de su primer estado imperfecto, más vale que nos dejemos de ciencia y sabiduría, temible espada que daña y hiere a su dueño cuando mano fuerte y experimentada no la esgrime". ${ }^{50}$ Es típico, según su opinión, que los pedantes se afanen en guardar como en un depósito las opiniones y saberes de los otros pedantes de modo que parecen sonreír de astucia sin darse cuenta de que lo más urgente sería hacerlos totalmente propios. De esta incapacidad de juicio, resulta lógico que se derive la de dialogar consigo mismo y con su realidad. La mayoría de los pedantes carecen de "sentido común"; por eso, insistirá Montainge, no resulta extraño que si no ha crecido el recto juicio y la cordura en el alumno, su latín y griego sólo

${ }^{48}$ Montaigne, Ensayos pedagógicos. 1952, Madrid, Ediciones de la Lectura, p. 40.

${ }^{49} \mathrm{Ibid}$, p. 45.

${ }^{50}$ Ibid, p. 53. 
le sirvan para volverse más necio y presumido que cuando estaba en casa. La escuela que no ayuda a crecer al alumno lo hace petulante. Estas ideas de Montaigne me parece que tienen más vigencia que nunca, sobre todo cuando se realiza una reflexión crítica del "paradigma educativo basado en competencias", que ha imperado en la denominada "sociedad del conocimiento". Y sobre todo, cuando se quieren ponderar el significado y alcance del aparato conceptual llamado "competencia social y ciudadana".

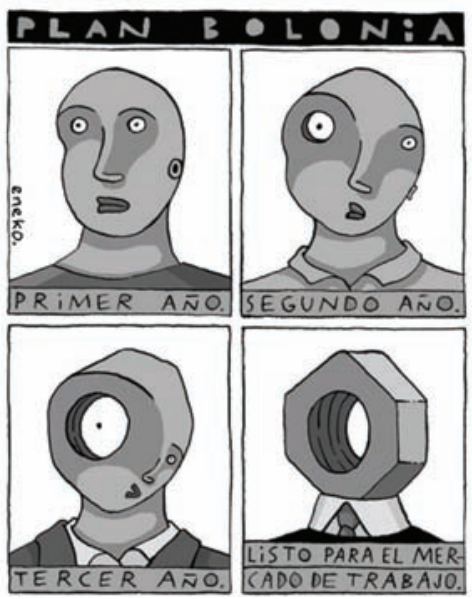

http://blogs.20minutos.es/eneko/post/2008/11/28/plan-bolonia

\section{La forma es fondo}

Durante el siglo XX, la psicología de la Gestalt dedicó grandes esfuerzos a entender la "problemática" relación entre la forma (figura-objeto), que nuestra atención tiende a destacar, y el resto que circunda (fondo). Algunos de sus estudios empíricos revelaron que no es posible captar el fondo sin la forma y que, cuando se altera el significante, también se hace lo propio con el significado. ¿Qué sucedería si el contenido se diluye en la forma? ¿Qué pasa cuando la forma se convierte en el fondo? En el caso de las competencias resulta significativo que muy pocos 
documentos reconozcan como "fundamental en el marco de las competencias" la necesidad de que los individuos piensen y actúen reflexivamente. "La reflexión involucra no sólo la habilidad de aplicar de forma rutinaria una fórmula o método para confrontar una situación, también la capacidad de adaptarse al cambio, aprender de las experiencias y pensar y actuar con actitud crítica". ${ }^{51}$ La mayoría de las veces, esta cuestión está prácticamente ausente. En el caso del Parlamento europeo, las "competencias clave se consideran igualmente importantes, ya que cada una de ellas puede contribuir al éxito en la sociedad del conocimiento". ${ }^{52} \mathrm{Si}$ atendemos al discurso, ¿el fin de la educación es el éxito? ¿Las competencias clave son todas igualmente importantes? ¿Es igualmente importante poseer la competencia digital que la capacidad para ponderar críticamente la propia experiencia y comprometerse con la comunidad? Consideramos que este modelo favorece la dilución de los fines educativos manteniendo las apariencias; colocan los intereses mercantiles como objetivo, pero quieren simular lo contrario. Para ello, incorporan la denominada competencia social y ciudadana, el sentido de iniciativa y espíritu de empresa, la conciencia y expresiones culturales. En otros casos, disponen al unísono el fondo y la forma educativa de modo que se pierden las posibilidades de distinguir entre medios y fines. Al hacer esto, reducen la educación a la esfera de la reproducción, nunca a la de la transformación y la disrupción.

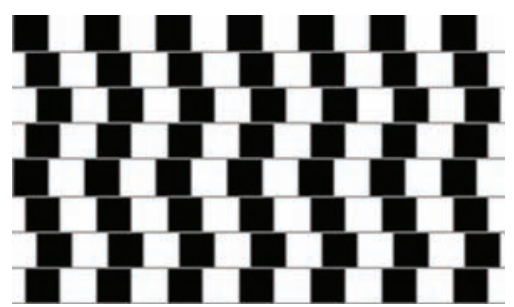

http://ilusionesopticas.org/paralelas/

${ }^{51}$ OCDE-DeSe-Cp, op. cit., p. 4.

${ }^{52}$ Parlamento europeo, Competencias claves, op. cit., p. 13. 


\section{La educación moral como tecnología educativa}

En el Menón se elabora, de manera rotunda, una de las preguntas más recurrentes de la educación moral: aquella sobre la posibilidad de enseñar la virtud. "Me puedes decir, Sócrates: ¿es enseñable la virtud?, ¿o no es enseñable, sino que sólo se alcanza con la práctica?, ¿o ni se alcanza con la práctica ni puede aprenderse, sino que se da en los hombres naturalmente o de algún otro modo?". ${ }^{53}$ La respuesta, en muchas ocasiones, ha sido negativa o ha quedado sin solución. Jacques Derrida, abatido por su enfermedad, otorgó una última entrevista antes de morir, en el año de 2004, en la que reflexiona sobre la fórmula "aprender a vivir". "Aprender a vivir es madurar y también educar: enseñar al otro, y sobre todo a uno mismo $[. .$.$] ¿Se puede aprender a vivir? ¿Se puede enseñar? ¿Se puede$ aprender, mediante la disciplina o la instrucción, por medio de la experiencia o la experimentación, a aceptar o, mejor, a afirmar la vida? [...] Entonces, bueno, para contestar sin más rodeos a su pregunta, no, nunca aprendí-a-vivir". 54

En realidad, existen varios paradigmas de educación moral. Según José M. Puig, se distingue: a) la educación moral como socialización; b) como clarificación de valores; c) la educación moral como desarrollo; d) la educación moral como formación de hábitos virtuosos; y, e) la educación moral como construcción de la personalidad moral. ${ }^{55}$ El modelo educativo basado en competencias, que aprobó el Parlamento europeo, está estrechamente vinculado con el de la educación moral como socialización; "entienden que la educación moral debe insertar o ajustar a los individuos a la colectividad a la que pertenecen. Describen la formación moral como un proceso mediante el cual los sujetos reciben de la sociedad el sistema vigente de valoraciones y normas, que se les imponen con una fuerza ajena a su conciencia y a su voluntad". ${ }^{56}$ En el texto aprobado por el Parlamento se acepta que las competencias sociales y cívicas "incluyen las personales, interpersonales e interculturales y

${ }^{53}$ Pla., Men., 70a.

${ }^{54}$ Jacques Derrida, Aprender por fin a vivir, 2007, Bs. As., Amorrortu, pp. 21-2.

${ }^{55}$ Cfr J. M. Puig, "Construcción dialógica de la personalidad moral”, Revista Iberoamericana de Educación, 1995, núm. 8, pp. 103-20.

${ }^{56} \mathrm{Ibid}, \mathrm{p} .103$. 
recogen todas las formas de comportamiento que preparan a las personas a participar de una manera eficaz y constructiva en la vida social y profesional, especialmente en sociedades cada vez más diversificadas, y, en su caso, para resolver conflictos". ${ }^{57}$ Este "enfoque" también incorpora algunas ideas de la educación moral como clarificación de valores y como desarrollo porque acepta la progresividad del juicio moral, la conflictividad que supone una sociedad multicultural y la urgencia de facilitar procesos personales de valoración. El análisis atento de los documentos que se han generado nos permite descubrir que el "fondo" de las "competencias sociales y cívicas" no es de ninguna manera la educación moral, entendida como formación de "hábitos virtuosos" o como "construcción dialógica de la personalidad moral", sino la "comprensión de los códigos de conducta y los usos generalmente aceptados en las distintas sociedades y entornos (por ejemplo, en el trabajo)". ${ }^{58}$ En este horizonte, adquieren significado la educación en derechos humanos y el multiculturalismo, sólo como herramienta al servicio de la cohesión social.

Esta "tecnificación" de la moral fue analizada desde hace muchos años por Max Horkheimer en su obra Crítica de la razón instrumental. Desde su perspectiva, la "noción de racionalidad" que sirve de fundamento a la sociedad industrial tiende a "aniquilar precisamente aquella substancia de la razón cuyo nombre se invoca a favor del progreso". ${ }^{59}$ La razón no se esfuerza ya en comprender los fines, incluso determinarlos, sino que reduce su función a la de regular la relación entre medios y fines. Esta situación hace que, en "la mayoría de los casos, ser razonable significa no ser testarudo, lo cual señala nuevamente una coincidencia con la realidad tal cual es. El principio de la adaptación se considera como cosa obvia". ${ }^{60}$

La educación moral nacida de la perspectiva instrumental es aparatosa en la misma proporción que hueca y conservadora. Se “encubre” en

\footnotetext{
${ }^{57}$ Parlamento europeo, Competencias clave para el aprendizaje permanente, op. cit., p. 23.

${ }^{58}$ Ibidem.

${ }^{59}$ Max Horkheimer, Crítica de la razón instrumental, 1973, Bs. As., Editorial Sur, p. 7. ${ }^{60} \mathrm{Ibid}$, p. 10.
} 
un discurso "aparentemente" integrador, mientras se esfuerza en modelar la conducta de los individuos de "acuerdo con los códigos y usos" dominantes. Al hacerlo, reduce significativamente las verdaderas posibilidades de lo humano, que siempre son heredas de la incertidumbre, el ingenio y la conciencia. Para alcanzar su "fin", se preocupa de desarrollar sofisticados sistemas de "medición del desempeño" y de "condicionar las respuestas" idóneas al sistema social. Se insiste de manera grandilocuente en la importancia de "aprender a comunicarse de una manera constructiva en distintos entornos, mostrar tolerancia, expresar y comprender puntos de vista diferentes, negociar sabiendo inspirar confianza, y sentir empatía" como medios del único fin que evidentemente no es la persona sino las necesidades mercantiles. ¿Y por qué no enseñarle de paso a los individuos a "gestionar su estrés y la frustración y de que los expresen de una manera constructiva? ${ }^{61}$ Lo dijo claramente Horkheimer: "el avance progresivo de los medios técnicos se ve acompañado por un proceso de deshumanización. El progreso amenaza con aniquilar el fin que debe cumplir la idea del hombre". ${ }^{62}$ ¿Qué podemos hacer?

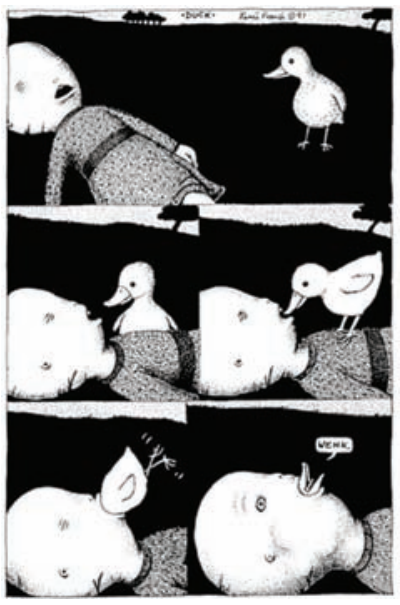

http://www.comicsreporter.com/index.php/resources/interviews/4288/

${ }^{61}$ Parlamento europeo, Competencias clave para el aprendizaje permanente, op. cit., p. 24.

${ }^{62}$ Max Horkheimer, op. cit., p. 7. 


\section{La construcción dialógica de la personalidad moral}

El ser humano nunca ha dejado de disfrutar del poder evocador de los mitos. Sus imágenes, personajes y acciones parecen transcurrir en "otro lugar" y en "otro tiempo" y, sin embargo, resultan muy cercanos. Son arquetipos de nuestra existencia que justifican el origen del mundo, de los hombres y de la muerte. Existen algunos que son extraordinarios por la agudeza psicológica de sus personajes, por la belleza literaria con la que fueron elaborados o por la profundidad del mensaje que nos proponen. Como lo ha dicho el ilustre educador, don Carlos de la Isla, es "difícil encontrar una expresión más intensa, significativa y cargada de evidencia sobre las angustias, los engaños y frustraciones del hombre contemporáneo que el mito de la caverna, narrado hace 25 siglos por Platón en su República" ${ }^{63}$ En este mito, los hombres se encuentran atados desde niños de modo que deben permanecer en una misma posición, mirando hacia delante, imposibilitados para regresar. Sobre el fondo de la cueva, se reflejan una serie de sombras que los prisioneros confunden como la realidad: "¿los prisioneros no tendrían por real otra cosa que las sombras de los objetos artificiales transportados?". ${ }^{64}$ Están sometidos y no se dan cuenta de su situación. De manera análoga, el modelo basado en competencias parece que busca, en última instancia, adaptar a estos hombres al status quo, para que se "conformen" con las sombras que le proyecta el "pensamiento único" y no sean factores transformación social.

La paideia platónica transita en sentido contrario y pretende una especie de "conversión". "Consiste en volver o hacer girar toda el alma hacia la luz de la idea del bien, que es el origen de todo". ${ }^{65}$ Este tipo de conocimiento, que no es equiparable con el dominio de conceptos abstractos, es el resultado de largos años de esfuerzo dialéctico que hace al hombre vivir conforme a la frónesis. Sócrates ya había reflexionado sobre esta noción, que permite el conocimiento del bien y su imperio sobre

\footnotetext{
${ }^{63}$ Carlos de la Isla, De esclavitudes y libertades, 2006, México, ITAM-Porrúa, p. 65. ${ }^{64}$ Pla., R., 514 b.

${ }^{65}$ Werner Jaeger, Paideia: los ideales de la cultura griega, 2008, México, FCE, p. 696.
} 
el alma. La única herramienta para fomentarla en sus discípulos fue el diálogo, que tanto los impresionaba. Las actitudes dialógicas de Sócrates revelaban su vocación "médica". Las preguntas y respuestas, fundamento de sus conversaciones, evidenciaban la convicción de que la palabra nace de la vida cotidiana y es un camino para develar el sentido de manera colectiva. "Existe cierta analogía interna entre el diálogo socrático y el acto de desnudarse para ser examinado por el médico o el gimnasta antes de lanzarse a la arena para el combate". ${ }^{66}$

En cierto pasaje del Teeteto, se discurre específicamente sobre el "arte de la mayéutica". Sócrates afirma que las parteras ofrecen drogas y "ensalmos" para acelerar los dolores de parto o para hacerlos soportables. Ayudan a dar a luz a las que tienen un mal parto. Inmediatamente, relaciona su arte con el de aquéllas, pues tiene las mismas características: "examina las almas de los que dan a luz, pero no sus cuerpos. Ahora bien, lo más grande que hay en mi arte es la capacidad que tiene de poner a prueba por todos los medios si lo que engendra el pensamiento del joven es algo imaginario y falso o fecundo y verdadero" ${ }^{67}$ Es razonable, entonces, suponer que un proceso educativo que utilice del método mayéutico sea profundamente crítico y reflexivo. No se puede imaginar en escenarios dogmáticos y expositivos, sino dinámicos y participativos. Implica un juicio respetuoso, pero radical, de las afirmaciones de los interlocutores.

En dicho diálogo, también se describe que la mayéutica es inseparable de la capacidad para formular preguntas y respuestas. Nace de una relación y de un diálogo sostenido. "Muchos, en efecto, me reprochan que siempre pregunto a otros y yo mismo nunca doy ninguna respuesta acerca de nada por mi falta de sabiduría, y es, efectivamente, un justo reproche". ${ }^{68} \mathrm{El}$ método mayéutico compromete, entonces, al guía o profesor a centrarse en el proceso interno de los estudiantes, mantener una relación cordial y conducir el proceso de comunicación: “es evidente que no aprenden nunca nada de mí, pues son

\footnotetext{
${ }^{66}$ Ibid., p. 411.

${ }^{67}$ Pla., Tht, 149a.

${ }^{68}$ Ibid., 150.
} 
ellos mismos y por sí mismos los que descubren y engendran muchos bellos pensamientos". 69

El diálogo tiene mucho de la danza, como lo decía con profundidad poética Martin Buber; es dinámico, impredecible, un camino que recorrer. En él se cifra la educación moral, nunca en las recetas de la razón instrumental. Las diversas amenazas que plantea la revolución postindustrial para la construcción de juicios propios, como resultado de la sobresaturación informativa, implicarán el reto más grande de la educación, el de la edificación de las condiciones que permitan a todo hombre o mujer acceder por sí mismos a su morada (einhausen). "Sólo se aprende por medio de la conversación". ${ }^{70}$ 